\title{
Active centromere and chromosome identification in fixed cell lines
}

Thian T. Beh ${ }^{1,2}$, Ruth N. MacKinnon ${ }^{3,4}$ and Paul Kalitsis ${ }^{1,2^{*}}$

\begin{abstract}
Background: The centromere plays a crucial role in ensuring the fidelity of chromosome segregation during cell divisions. However, in cancer and constitutional disorders, the presence of more than one active centromere on a chromosome may be a contributing factor to chromosome instability and could also have predictive value in disease progression, making the detection of properly functioning centromeres important. Thus far, antibodies that are widely used for functional centromere detection mainly work on freshly harvested cells whereas most cytogenetic samples are stored long-term in methanol-acetic acid fixative. Hence, we aimed to identify antibodies that would recognise active centromere antigens on methanol-acetic acid fixed cells.

Results: A panel of active centromere protein antibodies was tested and we found that a rabbit monoclonal antibody against human CENP-C recognises the active centromeres of cells fixed in methanol-acetic acid. We then tested and compared combinations of established methods namely centromere fluorescence in situ hybridisation (cenFISH), centromere protein immunofluorescence (CENP-IF) and multicolour FISH (mFISH), and showed the usefulness of CENP-IF together with cenFISH followed by mFISH (CENP-IF-cenFISH-mFISH) with the aforementioned anti-CENP-C antibody. We further demonstrated the utility of our method in two cancer cell lines with high proportion of centromere defects namely neocentromere and functional dicentric.

Conclusions: We propose the incorporation of the CENP-IF-cenFISH-mFISH method using a commercially available rabbit monoclonal anti-CENP-C into established methods such as dicentric chromosome assay (DCA), prenatal karyotype screening in addition to constitutional and cancer karyotyping. This method will provide a more accurate assessment of centromere abnormality status in chromosome instability disorders.
\end{abstract}

Keywords: Centromere, CENP-A, CENP-C, Immunofluorescence, Fluorescence in situ hybridisation (FISH), Multicolour FISH (mFISH), Neocentromere, Dicentric, Dicentric chromosome assay (DCA), Human erythroleukaemia (HEL) cell line

\section{Background}

One of the hallmarks of cancer is genome instability, often characterised by the presence of aneuploidy and genetic heterogeneity resulting from chromosome missegregation or defective DNA repair followed by the failure to enter cellular arrest or death $[1,2]$. Such genetic heterogeneity ranges from the extent seen in leukaemias, generally presented with simple chromosomal rearrangements, to carcinomas that are often complex [3, 4]. It is only with cumulative method improvements and technological

\footnotetext{
* Correspondence: paul.kalitsis@mcri.edu.au

'Murdoch Childrens Research Institute, Royal Children's Hospital, Parkville,

Melbourne, VIC 3052, Australia

2Department of Paediatrics, University of Melbourne, Royal Children's

Hospital, Parkville, Melbourne, VIC 3052, Australia

Full list of author information is available at the end of the article
}

advancements made over the past 60 years that we are able to better understand disease mechanisms, and then apply the knowledge to cancer diagnosis, classification, prognosis, treatment selection and monitoring after treatment using the combination of molecular pathology, molecular cytogenetics and genomics in cancer research $[5,6]$.

One such technical advancement is the combination of RNA or DNA fluorescence in situ hybridisation (FISH) with immunofluorescence, commonly used for detection of RNA or DNA together with the protein of interest in or on the same cell. Co-detection of both genetic and the protein (epigenetic) components is especially crucial in determining the activity status of a centromere - whether it is functional (active) or nonfunctional (inactive). The human centromere is a DNA- 
protein structure consisting of the repetitive $\alpha$-satellite DNA wrapping around nucleosomes containing CENPA that specify the inner kinetochore onto which other kinetochore protein complexes assemble [7]. A properly functioning centromere is essential for correct chromosome segregation during cell divisions.

For cytogenetic investigations in the research setting, combinations of FISH and multicolour FISH (mFISH) performed on fixed cells as well as immunofluorescence followed by FISH (Imm-FISH) performed on freshly harvested cells are routinely used. However, for the studies of the centromere regions, most antibodies raised against human centromere proteins do not recognise the epitopes of their targets after fixation in methanol-acetic acid despite using the method proposed by Earnshaw et al. [8]. This includes immersing cell preparations into a low ionic strength buffer to unravel the conformation of the compact chromosome to improve accessibility of target antigen and then returning the cells to buffer at physiological ionic strength to restore the chromosome morphology [8]. As for the current Imm-FISH carried out on freshly harvested cells, the morphology of the chromosomes is often distorted due to the involvement of the cytocentrifugation step $[9,10]$.

In this paper, we report on and discuss (1) the screening outcome of several kinetochore antibodies for fixed cells, (2) the difference between the proposed method involving immunocytochemistry, FISH and $\mathrm{mFISH}$, and the combination of other methods, and (3) the potential utility of the proposed method with the positive antibody, rabbit monoclonal anti-CENP-C, in identifying chromosomes with structural centromere defects in clinical samples of patients with congenital diseases or cancer as exemplified using T-47D, a breast cancer cell line, and SN12C, a renal cancer cell line, from the NCI60 cancer panel.

For the comparison of methods aforementioned, the human erythroleukaemia (HEL) cell line was used because MacKinnon et al. [11] have shown by FISH that HEL has two large, rearranged chromosomes positive for multiple nucleolar organiser regions and three rearranged chromosomes that contain centromere DNA sequences from two different chromosomes. HEL has been widely used for cell biology and differentiation studies in addition to the extensive data generated from a variety of techniques namely whole chromosome painting, single nucleotide polymorphism (SNP) array, OncoMap sequencing, mFISH, multicolour chromosome banding (M-BAND) and targeted FISH [11].

Autoimmune antibodies in the sera of scleroderma patients were known to react to intranuclear antigens of tissue sections but a subset were pinpointed to stain the centromere region after substantiation with mitotic cells by Moroi et al. [12]. In 1985, the anti-centromere antibodies (ACAs) from the sera of CREST (calcinosis, Raynaud's phenomenon, esophageal dismotility, sclerodactyly, telangiectasia) variant of scleroderma patients led to the discovery of the first three centromere proteins namely CENP-A (17 kDa), CENP-B $(80 \mathrm{kDa})$ and CENP-C (140 kDa), named from the lowest molecular weight to the highest [13].

Some ACAs had been shown to work on methanolacetic acid fixed cells. However, they usually recognise multiple centromere proteins depending on the individual serum and are limited in supply since they are restricted to individual autoimmune patients. Hence, ACAs are limited in their use for functional centromere identification where CENP-A and CENP-C are found exclusively on active centromeres but CENP-B is localised to the 17-bp CENP-B box of the centromeric repetitive DNA sequence regardless of its activity status $[10,14]$.

CENP-A and CENP-C are both part of the constitutive centromere-associated network (CCAN) that forms the inner kinetochore plate onto which other protein complexes assemble. CENP-A is a histone-H3 variant constituting the nucleosome core in a portion of the centromeric chromatin [15]. For CENP-A related studies, a mouse monoclonal antibody against human CENP-A (Clone: 3-19) generated by Ando et al. [16] has been widely used as it is known to give punctate signals that mark the inner kinetochore of the centromere region. Nonetheless, the binding of this antibody to CENP-A is obliterated if cells are fixed in methanolacetic acid solution [16]. On the other hand, a rabbit polyclonal serum generated against full-length human CENP-C by the Earnshaw laboratory was shown to work on methanol-acetic acid fixed cells as reported by Warburton et al. [9]. In addition, CENP-C perfectly colocalises with CENP-A and both are constitutive markers of active centromeres [17] but the supply of the rabbit serum against CENP-C is limited.

\section{Results and discussion \\ Centromere antibody screening}

With the awareness that most samples in the cytogenetic laboratories are stored long-term in methanol-acetic acid fixative and with the expectation that centromere status screening will provide useful information for these laboratories, we decided to screen several commercially available antibodies that target components of an active centromere using fixed HCT-15, a near diploid and lowly rearranged human colon cancer cell line [4].

From our screen, as summarised in Table 1, antibodies that did not show centromere signals on methanolacetic acid fixed cells are the rabbit polyclonal antibody recognizing phosphorylated Ser18 of CENP-A (Active Motif) and the rabbit monoclonal against BubR1 [EPR12259(2)] (Abcam), a spindle assembly checkpoint 
Table 1 List of antibodies targeting components of active centromere. Antibodies were first tested on non-fixative treated cells to determine optimal concentration or dilution for immunocytochemistry and then tested on cells stored in methanol-acetic acid fixative

\begin{tabular}{|c|c|c|c|c|}
\hline & Antibody & Species & $\begin{array}{l}\text { Concentration or } \\
\text { dilution }\end{array}$ & $\begin{array}{l}\text { Cells stored in methanol-acetic } \\
\text { acid }\end{array}$ \\
\hline 1 & BubR1 [EPR12259(2)] ab183496 (Abcam) & $\begin{array}{l}\text { Rabbit lgG } \\
\text { monoclonal }\end{array}$ & $0.527 \mu \mathrm{g} / \mathrm{ml}$ & No \\
\hline 2 & CENP-A (Clone: 3-19) & $\begin{array}{l}\text { Mouse lgG } \\
\text { monoclonal }\end{array}$ & $1: 500$ & No \\
\hline 3 & CENP-A phospho Ser18 (Active Motif) & Rabbit lgG polyclonal & $1: 400$ & No \\
\hline 4 & $\begin{array}{l}\text { CENP-C (Serum from rabbit 554; gift from William } \\
\text { Earnshaw) }\end{array}$ & Rabbit polyclonal & $1: 1000$ & Yes \\
\hline 5 & CENP-C [EPR15939] ab193666 (Abcam) & $\begin{array}{l}\text { Rabbit lgG } \\
\text { monoclonal }\end{array}$ & $0.677 \mu \mathrm{g} / \mathrm{ml}$ & Yes \\
\hline 6 & CENP-E [EPR4542(2)] ab133583 (Abcam) & $\begin{array}{l}\text { Rabbit lgG } \\
\text { monoclonal }\end{array}$ & $0.275 \mu \mathrm{g} / \mathrm{ml}$ & $\begin{array}{l}\text { Not homogeneous across all } \\
\text { chromosomes }\end{array}$ \\
\hline 7 & HEC1 [9G3] ab3613 (Abcam) & $\begin{array}{l}\text { Mouse lgG } \\
\text { monoclonal }\end{array}$ & $0.5 \mu \mathrm{g} / \mathrm{ml}$ & No \\
\hline
\end{tabular}

protein of the $B U B 1 B$ gene that plays a role in sensing proper chromosome-microtubule attachments during prometaphase to metaphase when it localises to the kinetochore (Fig. 1) [18]. The mouse monoclonal antibody against HEC1 (NDC80) [9G3] (Abcam), a protein of the NDC80 complex that stabilises microtubulekinetochore binding, was also negative for centromere signals on fixed cells. Rabbit monoclonal against CENPE [EPR4542(2)] (Abcam), a kinesin-like motor protein that accumulates at the kinetochore throughout metaphase [19], gave positive signals at the centromere regions but its staining was not homogeneous across all human chromosomes (Fig. 1), making it not ideal for the utilisation we were aiming for. Rabbit monoclonal against CENP-C [EPR15939] (Abcam) probed on fixed HCT-15 showed positive punctate signals (Fig. 1) similar to the signals seen in immunocytochemistry on nonfixed, cytocentrifuged cells even when it was used at a high dilution factor of 1 in 3,000 (data not shown).

\section{Combining cenFISH, CENP-IF and mFISH methods}

After validating that the rabbit monoclonal against human CENP-C worked on fixed cells, we then cross-linked the primary and secondary antibodies before performing $\alpha$ satellite FISH (cenFISH). This combined method of centromere protein immunofluorescence (CENP-IF) followed by cenFISH will be referred to as CENP-IF-cenFISH here onwards. In addition to the epigenetics and DNA-based information of the centromere activity, we believe that knowing the identity of the chromosomes would further add value to cytogenetic analysis. Hence, we attempted to carry out mFISH on the same cell spread on which CENP-IFcenFISH had been performed prior and to ensure that mFISH would work sufficiently well post-CENP-IFcenFISH, we compared the combination of methods as outlined in Fig. 2 using the HEL cell line (Fig. 3).
In general, the chromosome morphology of cytocentrifuged cells was not well-maintained compared to the metaphase spread of cells stored in methanol-acetic acid fixative (unpublished observation). However, we were still able to distinguish the chromosome identities with the mFISH procedure followed by image analysis (Fig. 3c) as seen in the comparable karyotypes generated from all methods (Fig. 3).

In our experiments, the cross-linking step with formaldehyde for antibodies against CENP-A and CENP-C prior to cenFISH in methods $\mathrm{C}$ and $\mathrm{D}$ respectively caused the red fluorescent signals at the active centromere regions to carry over into the mFISH analysis (Fig. $4 \mathrm{~b}$, lower panel). The green fluorescent signals from cenFISH were not detectable. Thus, by taking the carrying over of fluorescent antibody signal into account, we suggest the preparation of an additional sample but using a differently coloured secondary antibody against anti-CENP-A or anti-CENP-C for more accurate chromosome identification by $\mathrm{mFISH}$ post- CENPIF-cenFISH if necessary.

\section{Comparison between CENP-IF-cenFISH-mFISH with CENP-A and CENP-C}

Referring to Fig. 2, method $\mathrm{A}$ is the standard mFISH performed according to the protocol recommended by the manufacturer (MetaSystems) and it is a useful method to identify interchromosomal translocations but is unable to identify rearrangements involving $\alpha$-satellite DNA especially the ones without observable constrictions. However, with method $\mathrm{B}$, cenFISH followed by mFISH, multiple $\alpha$ satellite signals were observed on two large chromosomes designated (i) and (ii) (Fig. 3b). Even in combination with DAPI staining of the DNA where chromosome constrictions may be identified, identification of the centromere was proven to be not trivial in HEL cell line especially on the chromosome denoted (i). However, through methods 


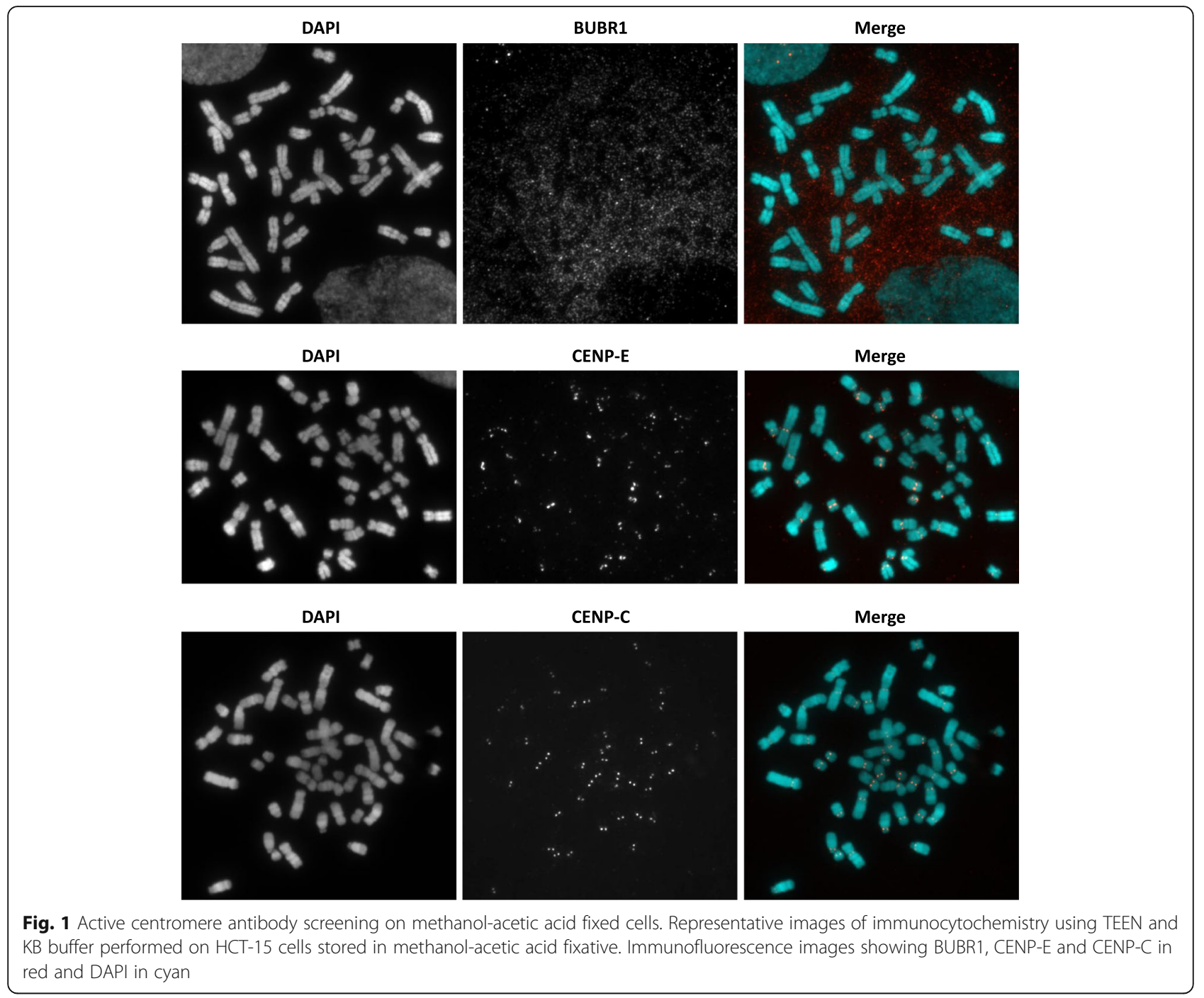

$\mathrm{C}$ and D (both are CENP-IF-cenFISH-mFISH), the presence of CENP-A and CENP-C signals indicates which of the two $\alpha$-satellite positive constrictions was the active centromere [Fig. 3c (i) and 3D (i)].

As reported in MacKinnon et al. [11], three derivative chromosomes, namely $\operatorname{der}(4 ; 20) \mathrm{t}(4 ; 11 ; 20)$ and another two that resulted from whole arm translocations between two chromosomes, $\operatorname{der}(5 ; 17)$ and $\operatorname{der}(10 ; 19)$, contain centromere sequences originated from two different chromosomes. We were able to detect the presence of two active centromeres based on CENP-C signals on at least one der(10;19) chromosome in 2 out of 6 metaphase spreads with method C [Fig. 3c (iii) and (iv)] and in 4 out of 7 metaphase spreads using method D [Fig. 3d (iii)]. $\operatorname{Der}(5 ; 17)$ and $\operatorname{der}(4 ; 20)$ chromosomes were always showing only a pair of punctate CENP-A and CENP-C signals. Besides, the der(20)t(11;15;20) [Fig. 3d (iv)] in the metaphase spread of Fig. 3d was the only der(20) that showed 2 pairs of signals for CENP-C out of 7 metaphases analysed. This raised the possibility of the centromere of chromosome 15 being present on der(20) which could not be tested by MacKinnon et al. [11].

\section{Detection of neocentric and functional dicentric chromosomes}

To demonstrate the method's utility, method D which used anti-CENP-C was carried out on two cell lines, T-47D and SN12C. T-47D is a breast cancer cell line known to us for having a stable neocentric chromosome while $\mathrm{SN} 12 \mathrm{C}$ is a renal cancer cell line that shows a high proportion of dicentric chromosomes in the metaphase spreads that we analysed for another study (in preparation). In both instances, our method was able to first detect centromere abnormalities within the metaphase spreads via CENP-IFcenFISH (Fig. 4a \& b, upper panels), followed by identification of the chromosomes that were involved in the final rearranged and centromere defect-bearing chromosomes (Fig. 4a \& b, lower panels). The neocentromere in T-47D 


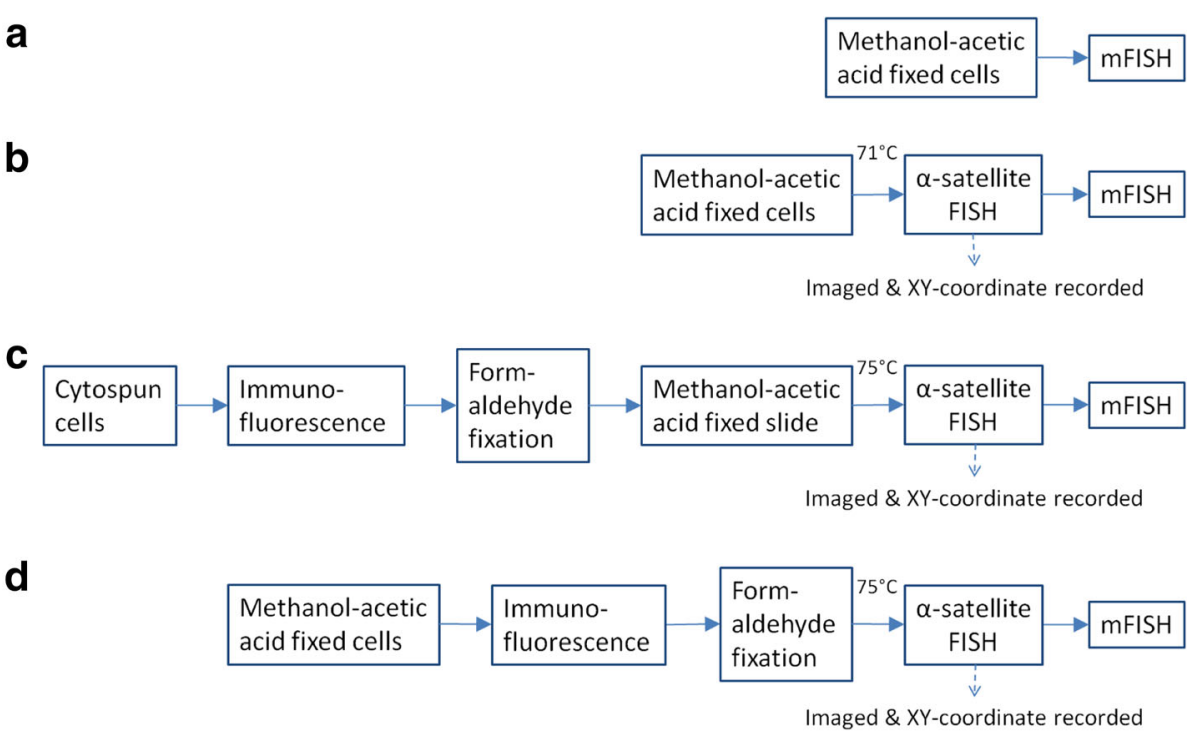

Fig. 2 Workflow combining and comparing mFISH, cenFISH and CENP-IF. a Standard mFISH as suggested by MetaSystems. b cenFISH-mFISH: pan-centromeric FISH with pTRA7 a-satellite probes, designated as cenFISH, imaged with metaphase spreads coordinates recorded and underwent $\mathrm{mFISH}$. c Freshly harvested cells swelled in hypotonic solution were cytospun onto microscope slide before immunofluorescence was performed using KCM buffer, cross-linked with $4 \%$ formaldehyde, fixed and denatured with methanol-acetic acid, aged, underwent cenFISH and subsequently mFISH. $\mathbf{d}$ Immunofluorescence using TEEN and KB buffer was performed on cells stored in methanol-acetic acid fixative, crosslinked with $4 \%$ formaldehyde before cenFISH and then mFISH was performed. Both methods $\mathbf{c}$ and $\mathbf{d}$ are CENP-IF-cenFISH-mFISH

was found to be on a segment of chromosome 3 and the neocentric chromosome was a product of rearrangement between chromosome 3 and 5 (Fig. 4a, lower panel) whereas the dicentric chromosome in $\mathrm{SN} 12 \mathrm{C}$ was formed from the rearrangement between chromosome 10 and 21 (Fig. 4b, lower panel).

In our study, we have demonstrated that our method, CENP-IF-cenFISH-mFISH, was able to (1) identify rearrangements implicating the centromeric DNA, (2) identify active centromere based on the presence of the constitutive kinetochore protein, CENP-C, and (3) reveal the identity of the chromosomes involved in the rearrangements for methanol-acetic acid fixed cells.

We hereby propose that this method will be particularly helpful in studying clinicopathologically complex groups of tumours, for example liposarcomas, potentially as an additional criterion in subcategorising them. Both atypical lipoma/well-differentiated liposarcoma (ALP-WDLPS) and dedifferentiated liposarcoma (DDLPS) are identified by the presence of similar marker chromosomes, namely the supernumerary ring or giant rod chromosome containing the amplified 12q14-15 region with amplification of the MDM2 and CDK4 genes. However, ALP-WDLPS is classified as having intermediate aggressiveness compared to DDLPS which is malignant [20]. In addition, a high proportion of ALP-WDLPS has a marker chromosome with a neocentromere in contrast to DDLPS that also has the marker chromosome containing amplified 12q14-15 but with alphoid-centromere [21, 22].
Functionally dicentric chromosomes with two active centromeres have been thought to be involved in the breakage-fusion-bridge cycle and have recently been suggested to also contribute to chromothripsis based on the modelling of a subset of pa ediatric acute lymphoblastic leukaemia (ALL) with intrachromosomal amplification of chromosome 21 [23]. Furthermore, in refining the treatment for patients of pa ediatric ALL, the presence or absence of a dicentric chromosome was considered alongside other cytogenetic and genomic criteria [24], and in a recent acute myeloid leukaemia (AML) study, the difference in median survival between patients with one dicentric (5.8 months) and those with three dicentric chromosomes (1.8 months) was shown to be significant [25]. Taken together, our method which has the capability to detect functional dicentric chromosomes in methanol-acetic acid fixed cytogenetic preparations could assist in understanding the involvement of dicentric chromosomes in disease mechanism and also in risk stratification of patients for the treatment of diseases other than childhood ALL and AML.

Furthermore, this method could also be applied to prenatal and congenital cases with chromosomal rearrangements containing centromere abnormalities that are not detected with current genomic technologies such as SNP microarrays and massively parallel sequencing [26]. An example of such chromosomal rearrangements is the isodicentric $\mathrm{Y}[\operatorname{idic}(\mathrm{Y})]$, commonly found in children with disorders of sex development. Patients presented 

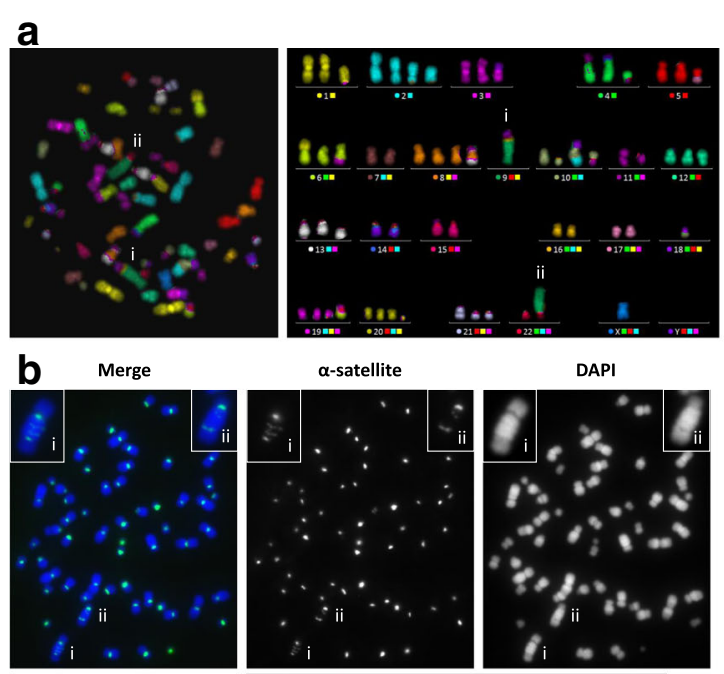

$\alpha$-satellite

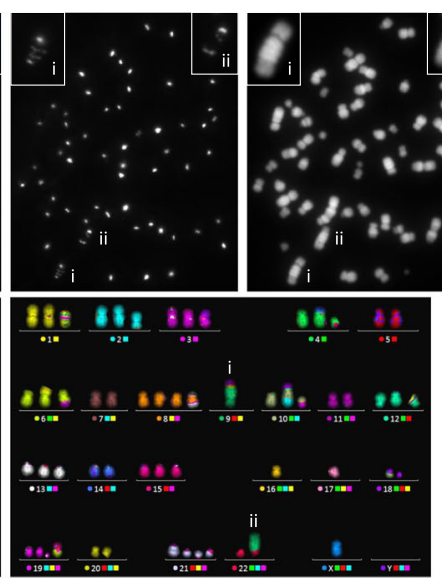

C Merge

$\alpha$-satellite

CENP-A DAPI
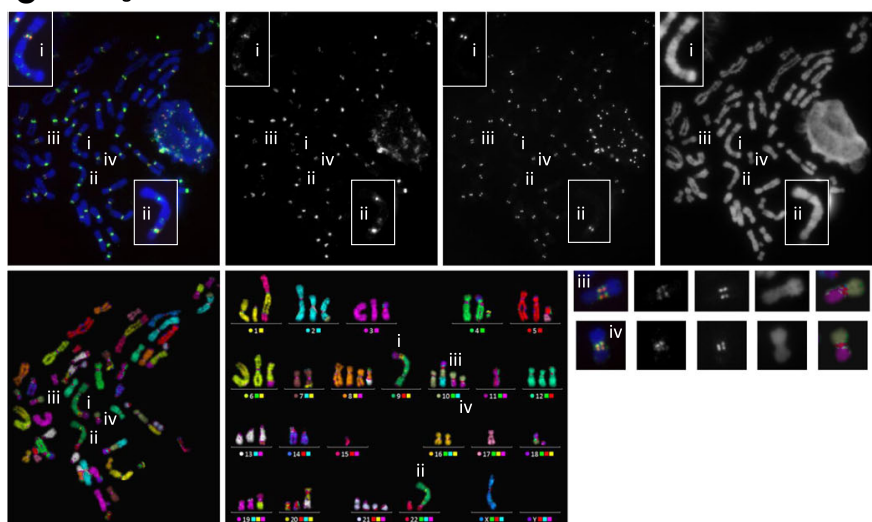

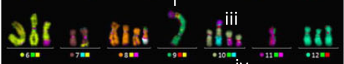
$\mathrm{C}^{\mathrm{x}}-\mathrm{a} \mathrm{B}$

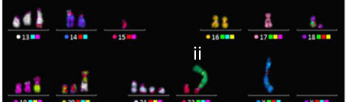

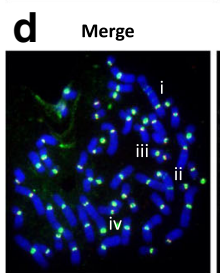

$\alpha$-satellite

CENP-C

DAPI
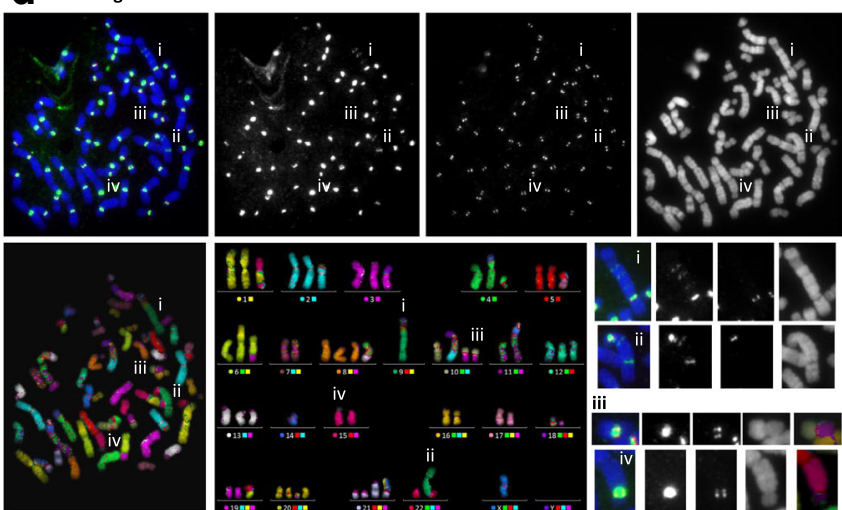

Ifi In 311

ile $\frac{16}{28}$

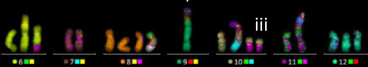

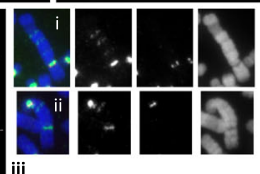

(a) is tiv

is

.

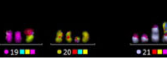

Fig. 3 (See legend on next page.) 
(See figure on previous page.)

Fig. 3 Representative images of HEL metaphase for each method, with marked (i) der(9) and (ii) psu dic(22;9). a Standard mFISH. Metaphase spread (left) and karyotype (right) in false colour. b cenFISH-mFISH. Upper panel: immunofluorescence images showing a-satellite (green) and DAPI (blue); insets are enlarged images of (i) der(9) and (ii) psu dic(22;9). Lower panel: metaphase spread and karyotype in false colour. c CENP-IFcenFISH-mFISH with CENP-A. Upper panel: immunofluorescence images of cytospun cells showing a-satellite (green), CENP-A (red) and DAPI (blue); insets are enlarged images of (i) der(9) and (ii) psu dic(22;9). Lower panel: metaphase spread and karyotype in false colour display. (iii) and (iv) are der(10;19) with two pairs of CENP-A signals. d CENP-IF-cenFISH-mFISH with CENP-C. Upper panel: immunofluorescence images showing a-satellite (green), CENP-C (red) and DAPI (blue). Lower panel: metaphase spread and karyotype in false colour display; (i) and (ii) are der(9) and psu dic(22;9) respectively while (iii) is der(10;19) and (iv) is der(20)t(11;15;20) (as named in MacKinnon et al. [11]) observed with two pairs of CENP-C signals

with $\operatorname{idic}(\mathrm{Y})$ are often mosaic with 45,X cells and a high proportion of females presented with 45 , X Turner syndrome have the $\mathrm{X}$ chromosome of maternal origin, which together suggest that $\operatorname{idic}(\mathrm{Y})$ is mitotically unstable [27, 28]. In addition, $\operatorname{idic}(\mathrm{Y})$ is the most common structural anomaly of chromosome $\mathrm{Y}$ in infertile men exhibiting an abnormal Y chromosome [28]. An azoospermic prospective father with $\operatorname{idic}(\mathrm{Y})$ may seek assisted reproductive technologies (ART) to achieve parenthood but he risks transmitting the $\operatorname{idic}(\mathrm{Y})$ to his offspring. Hence, the detection of $\operatorname{idic}(\mathrm{Y})$ is important for pre- and postnatal genetic counselling as well as for genetic screening and recommendation of ART for infertile men. However, for routine screening, anti-CENP-C CENP-IF used together with chromosome specific FISH probe would be a more economical approach.

Another important application of the method is in the refinement of dicentric chromosome assay (DCA), the gold standard for biodosimetry assessment of individuals after exposure to radiation [29]. The International Atomic Energy Agency recommends an analysis of more than 1000 cells for better ascertainment of dicentric
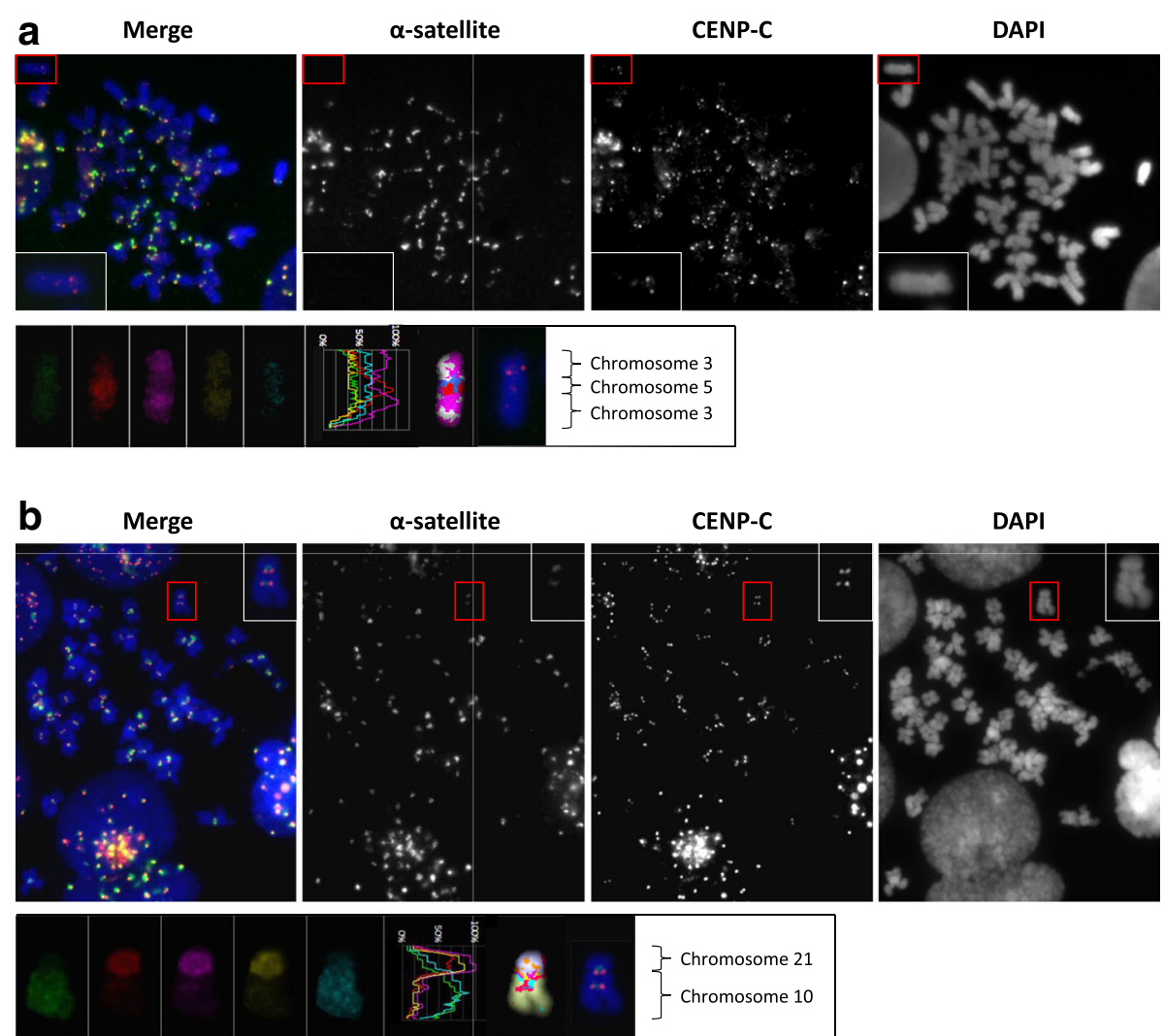

Fig. 4 CENP-IF-cenFISH-mFISH performed on cancer cell lines T-47D and SN12C with neocentric and dicentric chromosome respectively. a Upper panel: immunofluorescence images for T-47D showing a-satellite (green), CENP-C (red) and DAPI (blue); boxed in red is the neocentric chromosome and insets are enlarged images of the neocentric chromosome. Lower panel: $\mathrm{mFISH}$ colour profile of the neocentric chromosome indicating it is a rearranged chromosome containing segments from chromosomes 3 and 5. $\mathbf{b}$ Upper panel: immunofluorescence images for SN12C showing a-satellite (green), CENP-C (red) and DAPI (blue); boxed in red is the dicentric chromosome and insets are enlarged images of the dicentric chromosome. Lower panel: $\mathrm{mFISH}$ colour profile of the dicentric chromosome indicating it is a rearranged chromosome from chromosomes 21 and 10 
chromosome formation for low radiation dose of less than $100 \mathrm{mSv}$, equivalent to a computed tomography (CT) scan [30, 31]. A recent study by Abe et al. [31] reported that the analysis of 1000 metaphase spreads probed with cenFISH was sufficient to yield comparable precision to 2000 conventional Giemsa stained metaphases. However, these DCA methods only assess for the occurrence of a dicentric chromosome based on the presence of primary constrictions and centromere DNA, therefore, not providing any information on whether the affected chromosome contains one or two active centromeres which may have impacts on downstream genome instability. This gap of information could be addressed with the truncated version of our method D (excluding the mFISH step) as a DCA. With an additional $2 \mathrm{~h}$ and 40 min approximately for immunocytochemistry on top of cenFISH, it will provide the information on both the centromere DNA and its associated active kinetochore protein $\mathrm{CENP}-\mathrm{C}$, further improving the precision of the current DCA methods.

\section{Conclusions}

The CENP-IF-cenFISH method using pan-centromeric FISH probe and commercially available rabbit monoclonal anti-CENP-C to detect active centromere performed on methanol-acetic acid fixed cells is an improvement on the existing DCA methods and prenatal and congenital testings for chromosome structure anomalies such as isodicentric Y. Furthermore, the CENP-IF-cenFISHmFISH method which additionally reveals chromosome identity could potentially add diagnostic value and increase our understanding of disease mechanism if it was to be incorporated into established procedures including constitutional and cancer cytogenetic tests.

\section{Methods}

\section{Cell culture}

Cell lines namely HEL, HCT-15, T-47D and SN12C were cultured in Roswell Park Memorial Institute (RPMI) 1640 with $10 \%$ fetal bovine serum, $2 \mathrm{mM}$ L-glutamine, penicillin and streptomycin with $5 \% \mathrm{CO}_{2}$ at $37{ }^{\circ} \mathrm{C}$ [32]

\section{Cell preparation \& immunocytochemistry}

For immunocytochemistry performed on freshly harvested cells, colcemid (KaryoMAX, Thermo Fisher Scientific) was first added to cell medium to a final concentration of $0.1 \mu \mathrm{g} / \mathrm{ml}$ for $1.5 \mathrm{~h}$. Cells were harvested via mitotic shake-off and subjected to hypotonic treatment $(0.075 \mathrm{M} \mathrm{KCl})$ for $15 \mathrm{~min} .1500$ cells were used for each slide preparation. Cells cytospun onto the glass slides were washed thrice with cold $\mathrm{KCM}(120 \mathrm{mM} \mathrm{KCl}$, $20 \mathrm{mM} \mathrm{NaCl}, 10 \mathrm{mM}$ Tris-HCl pH 7.5, 0.5 mM EDTA, $0.1 \%$ Triton X-100) for 5 min each time and first incubated with mouse anti-human CENP-A (1:500) then followed by Alexa594 conjugated secondary antibody against mouse (1:1000) (Thermo Fisher Scientific), both diluted in KCM buffer with $1 \% \mathrm{BSA}$, at $37{ }^{\circ} \mathrm{C}$ for $1 \mathrm{~h}$ and $40 \mathrm{~min}$ respectively, with three $5 \mathrm{~min} \mathrm{KCM}$ buffer washes after each incubation. Cells were then crosslinked in KCM containing $4 \% \mathrm{v} / \mathrm{v}$ formaldehyde (Merck Millipore) for $10 \mathrm{~min}$ at room temperature (RT), washed twice with distilled water, briefly once and $5 \mathrm{~min}$ for another, and air-dried before being fixed in ice-cold methanol-acetic acid (methanol:acetic acid, 3:1 volume ratio) at $4{ }^{\circ} \mathrm{C}$ for $30 \mathrm{~min}$, air-dried and left to age for at least $48 \mathrm{~h}$ at RT. Antibody screening was performed on HCT-15 cells with the primary antibodies diluted according to Table 1 followed by Alexa594 conjugated secondary antibodies (1:1000) (Thermo Fisher Scientific) against the respective species. The cells were visualised without being fixed with methanol-acetic acid.

For immunocytochemistry on methanol-acetic acid fixed cells, cells were dropped onto glass slides and dipped immediately into TEEN buffer (1 $\mathrm{mM}$ triethanolamine- $\mathrm{HCl} \mathrm{pH}$ 8.5, $0.2 \mathrm{mM}$ Na EDTA, $25 \mathrm{mM}$ $\mathrm{NaCl}$ ) once the fixative had dried. TEEN buffer was changed twice, after $3 \mathrm{~min}$. Cells were blocked with $0.1 \%$ Triton X-100 (Sigma-Aldrich) and $0.1 \%$ BSA (Sigma-Aldrich) in TEEN at $37{ }^{\circ} \mathrm{C}$ for $15 \mathrm{~min}$ followed by incubation in rabbit anti-human CENP-C (1:3000) (Abcam) in TEEN at $37^{\circ} \mathrm{C}$ for $1 \mathrm{~h}$. Slides were washed with $\mathrm{KB}$ buffer (10 mM Tris- $\mathrm{HCl} \mathrm{pH} 7.7,150 \mathrm{mM}$ $\mathrm{NaCl}, 0.1 \% \mathrm{BSA}$ ) thrice, 4 min each time before incubating with Alexa594 conjugated secondary antibody against rabbit (1:1000) (Thermo Fisher Scientific) diluted in $\mathrm{KB}$ buffer at $37{ }^{\circ} \mathrm{C}$ for $40 \mathrm{~min}$. Slides were then washed twice with $\mathrm{KB}$ for $4 \mathrm{~min}$ each time before being fixed in KB containing $4 \%$ formaldehyde for $10 \mathrm{~min}$ at RT, washed twice with water, briefly once and $5 \mathrm{~min}$ for another, and then air-dried. For antibody screening, after the washing step post-secondary antibody incubation, slides were mounted with Vectashield antifade mounting medium (Vector Laboratories) added with DAPI before visualisation.

\section{Pan-centromeric probes}

The pTRA-7 plasmid containing pan $\alpha$-satellite DNA (previously described in [33]) was labelled with biotin using the dCTP analog conjugated with biotin (Thermo Fisher Scientific). $2 \mu \mathrm{g}$ plasmid DNA, $0.2 \mathrm{mM}$ dNTP mix (Promega), NEBuffer 2 (New England BioLabs Inc.), $0.1 \mathrm{mg} / \mathrm{ml} \mathrm{BSA}, 160 \mathrm{mU}$ DNaseI (New England BioLabs Inc.) and $20 \mathrm{U}$ DNA Polymerase I (New England BioLabs Inc.) were mixed into a final reaction volume of $30 \mu \mathrm{l}$ and incubated at $15{ }^{\circ} \mathrm{C}$ for $2.5 \mathrm{~h}$ for nick translation. The reaction was then inactivated at $75{ }^{\circ} \mathrm{C}$ for $20 \mathrm{~min}$. DNA was precipitated overnight at $-20{ }^{\circ} \mathrm{C}$ with $20 \mu \mathrm{g}$ of salmon sperm DNA (Thermo Fisher Scientific), 
0.1 volumes $\mathrm{NaOAc}$ and 2.5 volumes of $100 \%$ ethanol. Precipitated DNA was spun down, washed with $70 \%$ ethanol and subsequently air-dried. The DNA pellet was then resuspended in $40 \mu \mathrm{l}$ hybridisation buffer (30\% formamide, 2 X SSC, $10 \%$ dextran sulfate) before being denatured at $95{ }^{\circ} \mathrm{C}$ for $5 \mathrm{~min}$ and then placed on ice. This was a modification based on Roche's Nick Translation Kit protocol.

\section{FISH}

For cells that were to be probed directly, colcemid was added to the cell medium to a final concentration of $0.1 \mu \mathrm{g} / \mathrm{ml}$ for $1.5 \mathrm{~h}$. Cells were trypsinised, spun down for $4 \mathrm{~min}$ and washed once with phosphate-buffered saline (PBS) before being subjected to hypotonic treatment in $0.075 \mathrm{M} \mathrm{KCl}$ at $37{ }^{\circ} \mathrm{C}$ for $15 \mathrm{~min}$. Cells were then fixed by adding ice-cold methanol-acetic acid, spun down, resuspended with the fixative after discarding the supernatant and this process was repeated once and the pellet was resuspended in a final $200-800 \mu \mathrm{l}$ of fixative to yield an optimal cell density for metaphase spread preparation. Fixed cells were dropped onto glass slides and aged for at least $48 \mathrm{~h}$ at RT before performing FISH. Biotinylated probes against $\alpha$-satellites were codenatured with DNA on the slides at $71{ }^{\circ} \mathrm{C}$ for $5 \mathrm{~min}$ and incubated in a humidified chamber at RT for 16$18 \mathrm{~h}$. Slides were then (i) washed using $2 \mathrm{X}$ salinesodium citrate (SSC) buffer twice followed by 1 X SSC buffer thrice, each time at RT for 5 min, (ii) blocked with Tris-NaCl-Blocking (TNB) $[0.1 \mathrm{M}$ Tris- $\mathrm{HCl}$ pH 7.5, $150 \mathrm{mM} \mathrm{NaCl}, 0.5 \%$ w/v Blocking Reagent (Roche)] buffer at $37{ }^{\circ} \mathrm{C}$ for $30 \mathrm{~min}$, (iii) incubated with avidin conjugated with Alexa-488 (dilution 1:500) (Thermo Fisher Scientific), (iv) washed thrice with 4 X SSC with $0.05 \% \mathrm{v} / \mathrm{v}$ Tween-20 at $37{ }^{\circ} \mathrm{C}$ for 5 min each time and (v) mounted with Vectashield antifade mounting medium containing DAPI.

For cells that had undergone immunocytochemistry with CENP-A, aged slides were co-denatured with $\alpha$ satellites probes at $75{ }^{\circ} \mathrm{C}$ instead of $71{ }^{\circ} \mathrm{C}$ for $5 \mathrm{~min}$ and incubated in a humidified chamber at RT for 16-18 h. Subsequent steps were the same as aforementioned.

\section{$\mathrm{mFISH}$}

mFISH was carried out with 24 XCyte (MetaSystems) according to the manufacturer's instructions and with omission of a few early steps for slides that had undergone FISH and Imm-FISH. Slides that had undergone FISH only and immunocytochemistry followed by FISH were washed in $1 \mathrm{X}$ PBS at RT for $3 \mathrm{~min}$ and $2 \mathrm{X} \mathrm{SSC}$ at $70{ }^{\circ} \mathrm{C}$ for $30 \mathrm{~min}$, allowed to cool to RT for about $20 \mathrm{~min}$, washed in $0.1 \times \mathrm{SSC}$ at RT for $1 \mathrm{~min}$, denatured in $0.07 \mathrm{M} \mathrm{NaOH}$ at RT for $1 \mathrm{~min}$, washed in $0.1 \mathrm{X} \mathrm{SSC}$ followed by $2 \mathrm{X} \mathrm{SSC}$ at $4{ }^{\circ} \mathrm{C}$ for $1 \mathrm{~min}$ each wash and then sequentially dehydrated in 30, 50, 70 and $100 \%$ ethanol at RT for $1 \mathrm{~min}$ each before being air dried. Denatured 24 XCyte mFISH probes were then put onto the slides and incubated in a humidified chamber at $37{ }^{\circ} \mathrm{C}$ for 2 days. Post-hybridisation slides were washed in $0.4 \mathrm{X}$ SSC at $72{ }^{\circ} \mathrm{C}$ for $2 \mathrm{~min}, 2 \mathrm{X}$ SSCT ( $2 \mathrm{X} \mathrm{SSC}$ containing $0.05 \% \mathrm{v} / \mathrm{v}$ Tween-20) at RT for $0.5 \mathrm{~min}$ and rinsed briefly in water before being air dried and mounted with Vectashield antifade mounting medium containing DAPI for visualisation.

\section{Microscopy and analysis}

All images were taken using a Zeiss Axio Imager.M1 microscope/AxioCam Mrm camera. All Imm-FISH images were captured and analyzed with Axio Vs40 vs4.6.1.0 software (Carl Zeiss) while mFISH images were taken and analyzed with Isis colour fluorescence and FISH imaging system (MetaSystems).

\section{Abbreviations}

cenFISH: centromere fluorescence in situ hybridisation; CENP-IF: centromere protein immunofluorescence; Imm-FISH: immunofluorescence followed by FISH; mFISH: multicolour FISH; RT: room temperature.

\section{Competing interests}

The authors declare that they have no competing interests.

\section{Authors' contributions}

All experiments were carried out and the manuscript was drafted by $\Pi \mathrm{TB}$. The manuscript was reviewed and edited by PK and RNM. All authors read and approved the final manuscript.

\section{Acknowledgements}

We would like to thank Professor William Earnshaw at the Wellcome Trust Centre for Cell Biology, University of Edinburgh for the rabbit serum against CENP-C and Professor Hamish Scott at SA Pathology, Adelaide for the HEL cell line. This work was supported by the National Health and Medical Research Council (NHMRC), Australia Project Grant 1031089 and by the Victorian Government's Operational Infrastructure Support Program.

\section{Author details}

${ }^{1}$ Murdoch Childrens Research Institute, Royal Children's Hospital, Parkville, Melbourne, VIC 3052, Australia. ${ }^{2}$ Department of Paediatrics, University of Melbourne, Royal Children's Hospital, Parkville, Melbourne, VIC 3052, Australia. ${ }^{3}$ Victorian Cancer Cytogenetics Service, St Vincent's Hospital, Fitzroy, Melbourne, VIC 3065, Australia. ${ }^{4}$ Department of Medicine, St Vincent's Hospital, University of Melbourne, Fitzroy, Melbourne, VIC 3065, Australia.

Received: 6 February 2016 Accepted: 17 March 2016

Published online: 22 March 2016

\section{References}

1. Hanahan D, Weinberg RA. Hallmarks of cancer: the next generation. Cell. 2011;144:646-74.

2. Gordon DJ, Resio B, Pellman D. Causes and consequences of aneuploidy in cancer. Nat Rev Genet. 2012;13:189-203.

3. Hoglund M, Gisselsson D, Hansen GB, Mitelman F. Statistical dissection of cytogenetic patterns in lung cancer reveals multiple modes of karyotypic evolution independent of histological classification. Cancer Genet Cytogenet. 2004;154:99-109.

4. Roschke AV, Tonon G, Gehlhaus KS, McTyre N, Bussey KJ, Lababidi S, et al. Karyotypic complexity of the NCl-60 drug-screening panel. Cancer Res. 2003;63:8634-47.

5. Heim S, Mitelman F. A New Approach to an Old Problem. In: Heim S, Mitelman F, editors. Cancer Cytogenetics. 3rd ed. Hoboken: Wiley: 2010. p. 1-7. 
6. Bernheim A. Cytogenomics of cancers: from chromosome to sequence. Mol Oncol. 2010;4:309-22.

7. Kalitsis $\mathrm{P}, \mathrm{Choo} \mathrm{KH}$. The evolutionary life cycle of the resilient centromere. Chromosoma. 2012;121:327-40.

8. Earnshaw WC, Ratrie 3rd H, Stetten G. Visualization of centromere proteins CENP-B and CENP-C on a stable dicentric chromosome in cytological spreads. Chromosoma. 1989;98:1-12.

9. Warburton PE, Dolled M, Mahmood R, Alonso A, Li S, Naritomi K, et al. Molecular cytogenetic analysis of eight inversion duplications of human chromosome $13 q$ that each contain a neocentromere. Am J Hum Genet. 2000;66:1794-806.

10. Page SL, Earnshaw WC, Choo KH, Shaffer LG. Further evidence that CENP-C is a necessary component of active centromeres: studies of a $\operatorname{dic}(X ; 15)$ with simultaneous immunofluorescence and FISH. Hum Mol Genet. 1995:4:289-94.

11. Mackinnon RN, Wall M, Zordan A, Nutalapati S, Mercer B, Peverall J, Campbell $L$. Genome organization and the role of centromeres in evolution of the erythroleukaemia cell line HEL. Evol Med Public Health. 2013:2013:225-40

12. Moroi Y, Peebles C, Fritzler MJ, Steigerwald J, Tan EM. Autoantibody to centromere (kinetochore) in scleroderma sera. Proc Natl Acad Sci U S A. 1980;77:1627-31.

13. Earnshaw WC, Rothfield N. Identification of a family of human centromere proteins using autoimmune sera from patients with scleroderma. Chromosoma. 1985;91:313-21.

14. du Sart D, Cancilla MR, Earle E, Mao Jl, Saffery R, Tainton KM, et al. A functional neo-centromere formed through activation of a latent human centromere and consisting of non-alpha-satellite DNA. Nat Genet. 1997; 16:144-53

15. Hori T, Fukagawa T. Establishment of the vertebrate kinetochores. Chromosome Res. 2012;20:547-61.

16. Ando S, Yang H, Nozaki N, Okazaki T, Yoda K. CENP-A, -B, and -C chromatin complex that contains the I-type alpha-satellite array constitutes the prekinetochore in HeLa cells. Mol Cell Biol. 2002;22:2229-41.

17. Warburton PE, Cooke CA, Bourassa S, Vafa O, Sullivan BA, Stetten G, et al. Immunolocalization of CENP-A suggests a distinct nucleosome structure at the inner kinetochore plate of active centromeres. Curr Biol. 1997;7:901-4.

18. Baker DJ, Dawlaty MM, Wijshake $T$, Jeganathan KB, Malureanu L, van Ree JH, et al. Increased expression of BubR1 protects against aneuploidy and cancer and extends healthy lifespan. Nat Cell Biol. 2013;15:96-102.

19. Yen TJ, Li G, Schaar BT, Szilak I, Cleveland DW. CENP-E is a putative kinetochore motor that accumulates just before mitosis. Nature. 1992;359:536-9.

20. Bridge JA. The role of cytogenetics and molecular diagnostics in the diagnosis of soft-tissue tumors. Mod Pathol. 2014;27 Suppl 1:S80-97.

21. Garsed DW, Marshall OJ, Corbin VD, Hsu A, Di Stefano L, Schroder J, et al. The architecture and evolution of cancer neochromosomes. Cancer Cell. 2014;26:653-67.

22. Marshall OJ, Chueh AC, Wong LH, Choo KH. Neocentromeres: new insights into centromere structure, disease development, and karyotype evolution. Am J Hum Genet. 2008:82:261-82.

23. Li Y, Schwab C, Ryan SL, Papaemmanuil E, Robinson HM, Jacobs $P$, et al. Constitutional and somatic rearrangement of chromosome 21 in acute lymphoblastic leukaemia. Nature. 2014;508:98-102.

24. Moorman AV, Enshaei A, Schwab C, Wade R, Chilton L, Elliott A, et al. A novel integrated cytogenetic and genomic classification refines risk stratification in pediatric acute lymphoblastic leukemia. Blood. 2014;124:1434-44.

25. Sarova I, Brezinova J, Zemanova Z, Ransdorfova S, Izakova S, Svobodova K, et al. Molecular cytogenetic analysis of dicentric chromosomes in acute myeloid leukemia. Leuk Res. 2016:43:51-7.

26. Prakash S, Guo D, Maslen CL, Silberbach M, Milewicz D, Bondy CA, Gen TACl. Single-nucleotide polymorphism array genotyping is equivalent to metaphase cytogenetics for diagnosis of Turner syndrome. Genet Med. 2014;16:53-9.

27. Lange J, Skaletsky H, van Daalen SK, Embry SL, Korver CM, Brown LG, et al. Isodicentric $Y$ chromosomes and sex disorders as byproducts of homologous recombination that maintains palindromes. Cell. 2009;138:855-69.

28. Kim JW, Park SY, Ryu HM, Lee DE, Lee BY, Kim SY, et al. Molecular and clinical characteristics of 26 cases with structural $Y$ chromosome aberrations. Cytogenet Genome Res. 2012;136:270-7.
29. Crespo RH, Domene MM, Rodriguez MJ. Biodosimetry and assessment of radiation dose. Rep Pract Oncol Radiother. 2011;16:131-7.

30. IAEA. Cytogenetic dosimetry: applications in preparedness for and response to radiation emergencies, EPR-biodosimetry. Vienna: International Atomic Energy Agency; 2011.

31. Abe $Y$, Miura T, Yoshida MA, Ujiie R, Kurosu $Y$, Kato $N$, et al. Increase in dicentric chromosome formation after a single CT scan in adults. Sci Rep. 2015:5:13882.

32. Shoemaker $\mathrm{RH}$. The NCl60 human tumour cell line anticancer drug screen. Nat Rev Cancer. 2006;6:813-23.

33. Choo KH, Vissel B, Earle E. Evolution of alpha-satellite DNA on human acrocentric chromosomes. Genomics. 1989;5:332-44.

\section{Submit your next manuscript to BioMed Central and we will help you at every step:}

- We accept pre-submission inquiries

- Our selector tool helps you to find the most relevant journal

- We provide round the clock customer support

- Convenient online submission

- Thorough peer review

- Inclusion in PubMed and all major indexing services

- Maximum visibility for your research

Submit your manuscript at www.biomedcentral.com/submit
Biomed Central 